\title{
Application of AR Technology in Children Publishing
}

\author{
Xujin-E \\ Chongqing City Management College, Chongqing Shapingba Huxi University City 401331, China
}

Keywords: Augmented reality technology, AR technology, Children publishing, Book publishing, Digital era.

\begin{abstract}
Digital era of the rise of new media and multimedia integration trend is becoming more and more obvious, the rapid development of the Internet makes the dissemination of information more accurate and more quickly, the explosive growth in the amount of information makes people into the rapid absorption, digestion and feedback information of the fixed pattern. The traditional book publishing industry in the digital age under the impact of the reform of the horn is sounded, and a subtle change. Digital publishing and the rise of the Internet, the traditional publishing caused a huge impact and influence, the traditional book publishing industry wants to get rid of struggling to survive the difficulties provided shall be more thorough, adapt to the development needs of the times of the reform. This paper is based on the digital age a new technology of augmented reality technology to the book industry new form of exploration and research. The theme of this paper is based on the augmented reality technology in book publishing application status and development prospects by of augmented reality technology under the environment of traditional publications form, design language elements and domestic and foreign cases of serious discussion and analysis to find out the problems faced by the traditional publishing design under the new technical environment, solutions and innovative ideas, strive to traditional publishing design of future development put forward the reasonable suggestions, open up a new way of thinking.
\end{abstract}

\section{Introduction}

2016 was nearing the end of the year, said in 2016 the book publishing industry, surface placid, performance is not like newspapers and magazines in the media as a significant decline, but actually frequently filled. AR technology in the book publishing application, some people think that this is an important manifestation of book publishing format transformation [1]. As a publisher, in the book how to better in the publication of the application of this technique, it is worth our consideration.

AR is short for Augment Reality, we call it "augmented Reality" in Chinese, is a kind of real-time computing the position and Angle of the camera image and combined with the corresponding image, video, $3 \mathrm{~d}$ model of the technology. The technology is billed as a virtual world in which the virtual world is interactive.

AR technology has been around since 20 years ago, probably nothing new, and Google is a typical example of AR technology applications [2]. As the computing power of electronic products increases, the use of augmented reality becomes more and more widespread, involving military, medical, manufacturing and maintenance, entertainment and so on. Now, even a variety of apparel companies, Taboo's costume reality show, has applied AR technology to its advantage.

\section{Application of AR technology in publishing}

The advantages and disadvantages of AR technology in publishing applications. The application of AR technology in publishing cannot be regarded as fresh. As early as 2010, this paper discusses application of AR technology in domestic book publishing, to the 2013 Jiangsu book fair, China University of Mining and Technology press demonstrated a "mining machinery and hydraulic transmission", known as AR interactive technology paper number of mobile reading books, the camera books printed on the black and white excavator the image of the page, the display will appear 
3D stereo big red excavator, continuous rotation gear [3]. After that, AR technology began in many books, especially children's books in budding; Zhejiang children's publishing house, China children press and other publishers are trying to embed AR technology in library. In 2014, the relay Publishing House launched the "banana rocket science book", and it was the 10 volume, which could be said to be the first large-scale application of AR technology in books..

The combination of paper books and mobile Internet creates new commercial value. In the mobile Internet era [4], businesses grasp the big data, has become one of the most important basis for business valuation. AR in the sale of books, publishers can not only obtain profit also can obtain the user data and the user accurately established links from the traditional book sales, after the value-added benefits and commercial space is worth pondering.

Book cost is too high, book price is high. The cost of AR books is closely related to the number of pages on the AR interactive page, with many pages and high costs [5]. The more interactive and dazzling schemes, the higher the cost. The development of AR books faces more interaction, and the more prominent the technical value, the higher the book price, the more readers are away from the paradox.

AR books need a lot of auxiliary cooperation, to achieve higher difficulty. In the physical store sales, AR books if the same as the general book is not able to show the core of the show to the reader, which requires the display of the prototype machine and marketing staff to promote. In addition, the physical store to have a better WIFI environment, easy to experience the scene.

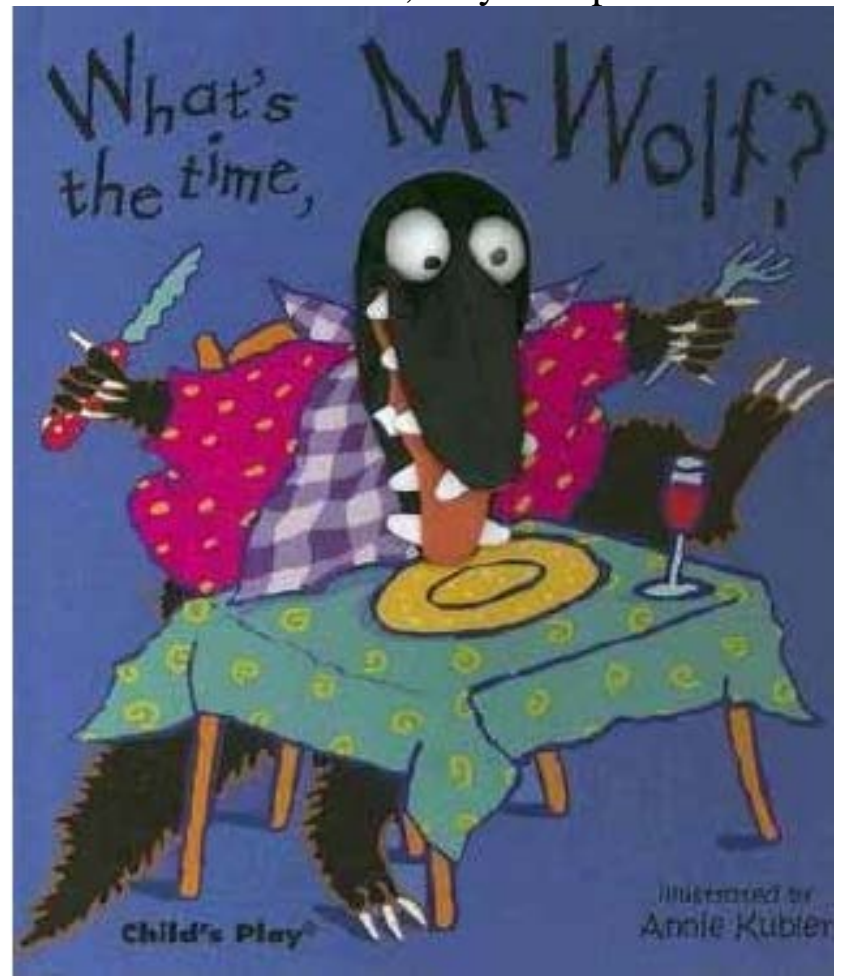

Fig. 1 Annie Kubler-What's the Time, Mr. Wolf? [With Finger Puppet] Child's Play

The display and display constrains the rapid development of AR technology books. AR book concept and technology matures, but did not drive the popularity of large quantities of AR books, one of the difficulties cannot be large-scale promotion is the promotion and display of the limitations. Unlike traditional books, AR books are displayed and displayed as a focal point. For example, in the promotion, the online method of illustration, so that readers quickly grasp the use of methods. In the ground store, the book is listed, the store synchronization coverage posters, KT version and paste, etc., above have detailed use of the details of the method, and with the book inside the page, can be directly experience. In the $\mathrm{W}$ workers $\mathrm{F}$ workers covered books store, you can directly scan the two-dimensional code on the code, on the spot to download, live experience. In the absence of $\mathrm{W}$ workers F covered books store, the scene staff can use the phone to explain the scene on the spot. However, many publishers have tried to show the video on the network AR effect, and shop 
marketing with, but the effect in general. And this has become the AR book to develop new products need to overcome the difficulties.

\section{Library’s Reading and Popularization Strategy under the Background of New Media}

Reading needs are the prerequisites and basis for library reading and promotion. Reading needs can be spontaneous ownership of users, and many are new media technology development or derived. With the progress of technology, such needs have been easily beyond the boundaries of time and space, many users want to enjoy anytime, anywhere access to reading services or information extraction, which requires the library in the reading service process, to provide timely communication, warm service, In place of feedback and targeted personalized service. New media in the promotion of publicity to enhance the attractiveness of information to stimulate the user's interest to expand the amount of reading, WeChat, BLOG, QQ group are new media exchange platform, three-dimensional, interesting, professional and so on can be improved. In addition, we must pay full attention to the role of the database system, fully tap customer information, intelligent, personalized custom services, and improve the user's loyalty to the library.

The cost of the AR book is closely related to the number of pages in the AR interaction page. The more pages, the higher the cost, but not directly. The program framework is basically the same, the more the content the higher the cost, such as the production of three-dimensional model, interactive point of the creative planning more expensive. The significance of the use of education in the way compared with the VR, the advantage is not obvious. Compared with the traditional paper publications, the price is much higher, for many parents, spend this extra money is not buy it. In the DangDang page search AR books, the biggest sales volume is the relay press "banana rocket scientific picture book", in its sales page, there is a clear description: in accordance with the book back cover instructions, download APP "banana rocket AR" application, The series of "we became astronauts," the last page to start to find the AR logo, with the software box to include it, that is, to see the spacecraft into the sky, slightly change the book orientation (AR logo can not deviate from Camera frame), we can see the full range of spacecraft structure and lift, decomposition, astronauts, such as the whole process of space stroll, but also with sound effects. The whole 3D image is actually a centralized stereoscopic presentation of the entire book content. The series also involves buildings, dinosaurs and many other popular elements, intense fighting scenes, play action, etc., can be displayed by finger operation in front of a lot of the contents of the book extension. This set of books in the Dangdang limited time to grab, is 5.9 fold sales, priced at 116 much higher than paper books. In addition to the price a little expensive, many buyers comment: 3D effect is good, there are fresh, but a book can only see a 3D presentation, too little.

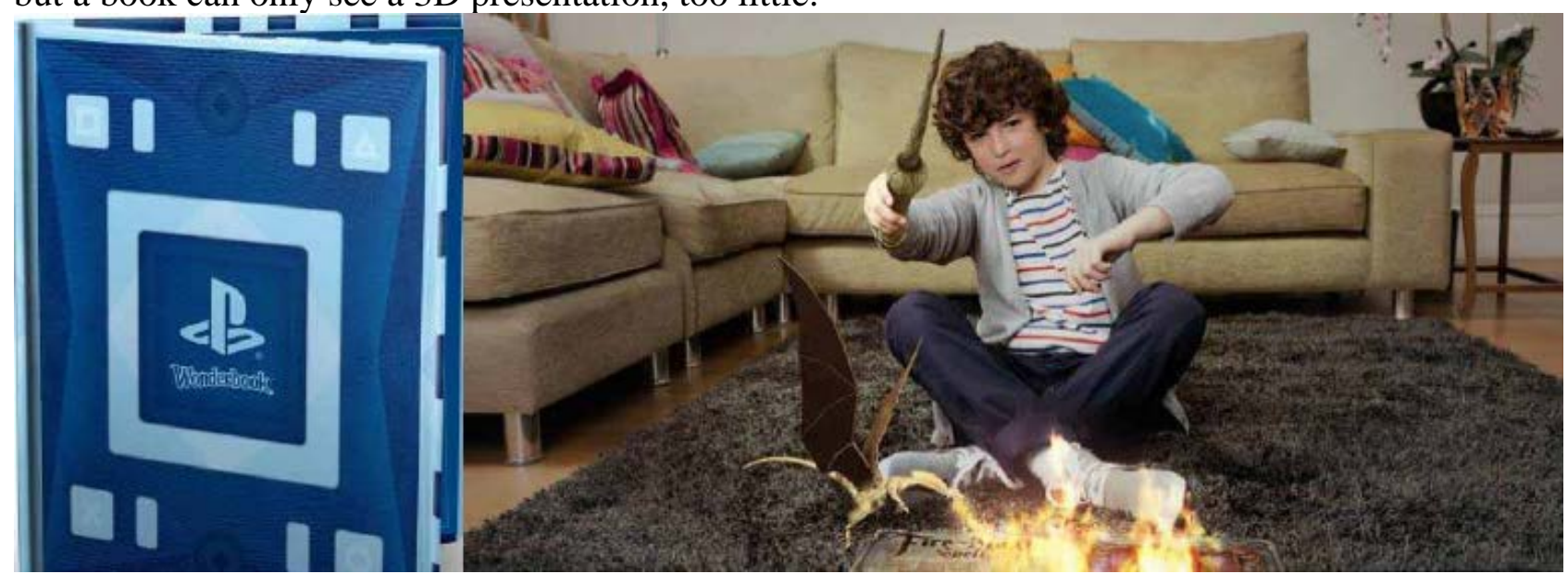

Fig. 2 Fantasy book

No matter what technology, the future development of science and technology to what extent, pay attention to the content of the book itself is the hard truth, technology is the carrier of communication, 
is the transmission of the media. The prospect of children's publication is no longer the world of paper publishing, but its high-quality content is the core of various carriers.

First of all, in the process of thinking, the reader should be placed in the main position. The reader's psychological thoughts and behavior influence the sales of products and economic value, so to carry on the classification according to occupation and age of the reader, the reader fully meet the taste and aesthetic values, but also know the reader's heart, often communicate with readers. In addition, I have to change my mind, use the product in the reader's position and communicate on the basis of the product. It is one of the means to check the effectiveness of the system design.

Second, the concept is set as a whole. The main paper books and augmented reality technology information research direction connection, market position and readers; it is necessary to consider the readers in the reading experience and feeling, and thinking from the interactive effects, 3D animation, the core content, form, sound effect and so on, to meet the readers in the visual sense.

Although the strengthening of reality books is a new vocabulary, but it has a very strong cross-border characteristics: such as from the fine programming skills to emotional sublimation, from the traditional paper books to high-tech three-dimensional products, from application technology to psychology; Enhance the reality of books is in the context of the unity of opposites, and their links at all links is the key to the problem where the designer is the innovation of the Department. Therefore, the link between the links, it is necessary to coordinate and have innovative, common composition of the overall design of the product.

\section{Summary}

New technology is the development of transformation and upgrading, integration and development of important support. I believe that publishers should seize such as AR, VR such a new technology, increase research and application efforts, and strive to find the content and technology fit point, the use of technology to make the content of the full play. I believe that the effective use of new technologies will greatly enhance the competitiveness of books and products. The emergence of the Internet, so that books and other media crisis, book sales gradually decline, the number of bookstores are also reduced, for which many people generally feel that paper publications will be difficult to survive under the impact of digital publications, , The paper industry's publishing industry is facing challenges and reforms. In high-tech today, intelligent terminal equipment has been integrated into people's lives. The Internet has contributed to the development of the economy and has brought convenience to people's lives. At present, e-books will not completely replace the paper books in people's lives in the occupied position, at least, we can predict that in the future for a long period of time, paper version and electronic version of the book will be A situation of both competition and cooperation.

\section{References}

[1] Von A R, Allemann Y, Sartori C, et al. Right ventricular dysfunction in children and adolescents conceived by assisted reproductive technologies. Journal of Applied Physiology, Vol. 118(2015) No. 10, p. 1200.

[2] Gillespie, S. M. Characteristics of females who sexually offend: a comparison of solo and co-offenders. Vol. 27 (2015) No..3 p. 284.

[3] Arensbergen, Pleun Van, I. V. D. Weijden, and P. V. D. Besselaar. Gender differences in scientific productivity: a persisting phenomenon?. Scientometrics, Vol. 93 (2012) No.3, p. 857-868.

[4] Carpenter, Ashley R. Ultrasound Imaging of the Murine Kidney. Methods in Molecular Biology, Vol. 886(2012), p. 403.

[5] Surhone L M, Tennoe M T, Henssonow S F, et al. Pekka Arbelius. (2011). 